\title{
AS HAITIANAS NA ESCOLA: O PESO DO PASSADO, A DUREZA DO PRESENTE E A ESPERANÇA NO FUTURO
}

\author{
AleXANDRe Guilherme \\ LUCAS RECH DA SILVA \\ Henrique Caetano Nardi \\ Pontifícia Universidade Católica do Rio Grande do Sul (PUCRS), Porto \\ Alegre, Rio Grande do Sul, Brasil
}

\begin{abstract}
Resumo: Este artigo, fruto de um estudo de caso, tem como objetivo abordar a violência de gênero no contexto migratório haitiano para o sul do Brasil, analisando as trajetórias e o cotidiano de duas jovens estudantes haitianas, por meio de entrevistas realizadas utilizando os princípios da história oral. Para isso, levantamos um breve histórico do significado da migração (diáspora) para o povo haitiano e as mudanças epistemológicas no campo de estudos migratórios, no que tange à presença da mulher nesses estudos, para então, refletirmos sobre a violência de gênero evidenciada nas narrativas das estudantes participantes da pesquisa e de como a instituição escolar não tem atuado nessa questão.
\end{abstract}

Palavras-chave: Migração haitiana. Gênero. Educação. Violência.

\section{INTRODUÇÃO}

Movimentar-se pelo planeta, desde os princípios da vida na Terra, permitiu que a humanidade pudesse se desenvolver e superar inúmeras adversidades ao longo da história. Por razões climáticas, de escassez de alimentos ou conflitos entre grupos, homens e mulheres estiveram em constante movimento. Portanto, migrar é parte da história humana, logo deveria ser encarada como um direito. Pensando nessa perspectiva, este trabalho analisa um recorte de pesquisa que se propôs a estudar a inclusão dos estudantes oriundos dos fluxos recentes de migração na Educação Básica na cidade de Caxias do Sul, Rio Grande do Sul.

Nos últimos anos, em virtude do crescimento econômico vivido nos primeiros anos do século XXI, o Brasil se tornou um país de destino atrativo para imigrantes de diversas partes do globo. Certamente, essa nova onda imigratória é de menores proporções que as anteriores, especialmente se a compararmos com aquela do final do século XIX e começo do XX, constituída por europeus, e com as migrações nos países desenvolvidos nos últimos anos.

Essa nova onda migratória para o Brasil apresenta uma particularidade por compreender majoritariamente indivíduos de países latino americanos e caribenhos, como é o caso do Haiti, bem como de países africanos, caso do Senegal. Assim sendo, o 
novo posicionamento do Brasil como parte dos BRICS, e o entendimento que o país despontava como potência emergente (utilizamos aqui o passado, em razão da crise econômica e do aumento do desemprego nos últimos dois anos), que atraiu um maior número de refugiados e imigrantes econômicos. Isso parece ser algo novo, dado que até então apenas países mais desenvolvidos enfrentavam essa situação, e os próprios brasileiros emigravam para países desenvolvidos por várias décadas, dado que o país enfrentava problemas de ordem política, social e econômica e que voltou a enfrentar após a destituição da presidenta eleita Dilma Rousseff.

Durante o período de crescimento econômico dos governos Lula e o primeiro mandato de Dilma Rousseff, deu-se o auge da migração haitiana para o Brasil, facilitada pela concessão do visto humanitário ao povo haitiano em decorrência do terremoto que abalou a capital Porto Príncipe no início do ano de $2010^{1}$. Essa modalidade de visto é prevista na Lei n 6.815/1980 e revista na nova Lei de Migração, n¹3.445 Lei/2017, sendo concedido pelo Ministério das Relações Exteriores e gerenciado pelo Conselho Nacional de Imigração (CNIg) vinculado ao Ministério do Trabalho. Com essa abertura jurídica e burocrática, um grande contingente de imigrantes haitianos passa a buscar o Brasil como país de destino.

As regiões sudeste e sul foram as que receberam o maior número de imigrantes haitianos (BRASIL, 2015, p. 59). No estado do Rio Grande do Sul a cidade de Caxias do Sul (Caxias) se tornou, em decorrência da economia forjada majoritariamente na indústria metal-mecânica, um dos principais locais de destino de imigrantes haitianos, bem como imigrantes oriundos de outros países como Senegal e Gana. Esses novos imigrantes são, em sua maioria, homens que migraram por motivação econômica-laboral, em busca de melhores postos de trabalho que os possibilitasse alcançar melhores condições de vida (HERÉDIA, 2015). A indústria da cidade soube, de forma muito eficaz, e por vezes até abusiva, absorver esses trabalhadores (GUILHERME, CASARTELLI, SILVA; FRAGA 2017) que, devido à sua condição de vulnerabilidade (MONTEIRO 2011, STANDING 2014), estão sujeitos a diversas formas de violência, inclusive aquelas associadas ao trabalho precarizado.

Dos imigrantes haitianos que conseguiram inserção no mercado de trabalho da cidade, uma parcela pequena teve a oportunidade de reagrupar suas famílias, trazendo para o Brasil esposa e filhos. Configurando-se, dessa forma, como famílias transnacionais reagrupadas que, segundo Machado, Kebbe e Silva (2008, p. 80):

[...] não pressupõe nenhuma tipologia nem modelo, mas um princípio de organização baseado na relação de seus membros espalhados por mais de um país. No mais das vezes, o que se diz como "família transnacional" não passa de uma forma de relação calcada numa espacialidade distinta, marcada pela experiência migratória (MACHADO; KEBBE; SILVA, 2008, p. 80).

Logo, essas famílias passam a buscar sua inserção na sociedade e procurar pelos serviços de saúde, educação e seguridade social, bem como por atividades de trabalho, lazer e todas as outras com as quais qualquer cidadão pode e tem direito de estar vinculado. Considerando isto, o foco deste estudo de caso foi compreender como estudantes imigrantes de ensino médio percebem e interpretam suas experiências de 
migração e de serem estudantes em Caxias do Sul, e quais violências aparecem nesse contexto. Para tanto, buscamos reconhecer as diferentes violências que motivaram o processo de mobilidade das famílias desses estudantes, bem como as possíveis violências às quais tenham sido submetidas na cidade de destino. Utilizamos violências no plural por entendermos que existem diversas formas de expressão das mesmas, ou seja, elas podem se manifestar estruturalmente, culturalmente, fisicamente e psicologicamente. Para isso, nos apoiamos nos estudos sobre violência de Frantz Fanon $(1952,1963)$ e Johan Galtung $(1976,1976,1996)$. Sobre as diferentes formas de violência e como são entendidas por estes autores, discorreremos mais adiante no texto. Todavia, o foco do recorte destacado neste texto está centrado nas violências que estão relacionadas e ocorrem em função das relações de gênero e como elas emergem nas entrevistas com as participantes da pesquisa.

Destarte, para entender a condição de migração destas estudantes haitianas e o que constitui o processo de mobilidade para o povo haitiano, é primordial conhecer e compreender um pouco das dinâmicas culturais desse povo. Assim, neste trabalho, antes de explicitar os caminhos e resultados da pesquisa, traçamos um breve panorama sobre: alguns aspectos da cultura haitiana que colaboram para o entendimento da complexidade do processo de mobilidade vivido pelas estudantes participantes da pesquisa; as transformações epistemológicas ocorridas no âmbito dos estudos migratórios, especificamente sobre a visibilidade das migrações de mulheres, para, então, compreender as diferentes percepções destas estudantes a partir das suas narrativas e como a violência de gênero afeta estas trajetórias.

\section{A DIÁSPORA HAITIANA}

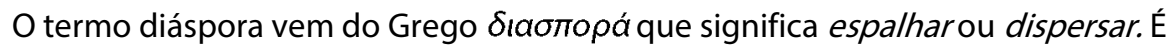
um termo usado normalmente para se referir a movimentos populacionais de grupos que migram da terra natal para outras. Exemplos clássicos disso são: a saída dos judeus de Israel, dos gregos de Constantinopla em tempos antigos, e dos irlandeses e escoceses no século XIX. Esse movimento de imigração em massa, a saída de uma grande proporção de uma população de sua terra natal para o exterior, sempre é causada por sérios problemas políticos, sociais e econômicos, que forçam indivíduos e famílias a deixarem seus lares. Entretanto, essa saída forçada de seus países não significa que deixem sua língua, cultura e história para trás, pelo contrário, muitas vezes esses elementos se tornam extremamente importantes para aqueles e aquelas que vivem a diáspora, porque ajudam na continuação e preservação de suas identidades.

Assim, entender as razões da diáspora haitiana e como ela interage com a história e cultura haitiana é indispensável para que possamos analisar compreensivamente os diferentes olhares desse povo sobre o mundo e as características das relações que esse povo estabelece com os locais de migração. De acordo com Handerson (2015, p. 54), o termo diáspora "dá forma, sentido e constitui o mundo social haitiano", e ainda está "associado à mobilidade transnacional como constitutiva da trajetória de vida das pessoas e dos horizontes de possibilidades delas". Dessa forma, o termo diáspora assume diferentes formas e significados para o povo haitiano.

Também, segundo o autor supracitado, o termo passa a ser usado por haitianos somente em meados da década de 1980, em Nova York, mobilizado por padres como 
dispositivo político para reivindicar direitos nos Estados Unidos e denunciar a ditadura no Haiti, sendo assim imprescindível para a construção do sentimento de identidade e da consolidação da comunidade haitiana. Nesse contexto, o termo diáspora é essencial para:

a articulação de projetos comunitários de jornais, televisões e associações dos haitianos nos Estados Unidos. Foi uma forma encontrada para descrever suas experiências e constituir uma agenda política. No espaço nacional haitiano, o uso do termo iniciou a partir do retorno, em 1986, dos compatriotas exilados durante a ditadura dos Duvaliers. Em 1990, tinha-se generalizado o uso do termo diáspora, tornando-se comum entre os haitianos no Haiti e fora dele. Nesse mesmo período, ele se integrou ao vocabulário de uma das línguas oficiais do país caribenho, o créole, escrito com " $y$ ", dyaspora. (HANDERSON, 2015, p. 55).

Portanto, no contexto da cultura haitiana, a diáspora se configura como um processo social desejado e almejado. Migrar é poder avançar, e isso mostra não apenas um esforço individual, mas principalmente coletivo, para alçar o indivíduo, sua família e a comunidade à qual pertencem, a um outro status. Além disso, a diáspora haitiana, ou "o diáspora"(aquele que emigra) haitiano, não deixa de participar da vida social e política do Haiti, visto que, de acordo com Handerson (2015), praticamente a metade da população haitiana vive fora do país ${ }^{2}$, e é responsável por parte significativa do dinheiro que circula em território haitiano.

Quando funcionários da Agência de Câmbio -CAM ou Western Union passam de casa em casa para entregar remessas em dólares, euros ou mercadorias, produtos alimentícios (arroz, feijão, azeite, etc.) enviados por residentes aletranje (no exterior), os vizinhos costumam dizer que diáspora chega à casa ou entra na casa. Geralmente, parte deles ou mesmo o dinheiro são compartilhados com alguns vizinhos, conhecidos ou familiares. (HANDERSON, 2015, p. 63).

Portanto, compreende-se que o projeto migratório no Haiti não é apenas individual, mas também coletivo, visto que mobiliza famílias e comunidades e que é reconhecido como um setor importante da economia do país ${ }^{3}$. Lançar-se ao estrangeiro é poder ajudar a família e a comunidade a sair da condição de escassez de recursos e pobreza, e portanto, tem raiz e uma forte motivação de pertencimento coletivo que se constrói na subjetividade do cidadão haitiano, criado a partir de um sentimento de solidariedade e de comprometimento comunitário.

Handerson (2015) também aponta que há diferentes categorias para os paísesdestino, que variam de acordo com questões econômicas e culturais, "países brancos/não brancos", "países grandes/pequenos", sendo que se referem, basicamente, ao desenvolvimento econômico do país de destino. Essa diferença entre os lugares de destino também se reflete no status hierárquico do diáspora no Haiti, pois altera a condição econômica dele, a moeda que envia e o tipo e qualidade dos produtos que envia. O Brasil pode ser encarado de diferentes formas, dependendo do contexto, mas no geral é tido como um país intermediário, não tão qualificado quanto França, Estados Unidos ou Canadá, mas não tão desvalorizado como Equador, República Dominicana e Chile. Isso se dá em função da moeda não tão valorizada ou porque o salário mínimo é 
irrisório, tornando difícil a economia para realizar remessas ao Haiti. Isso vai de encontro com o nosso entendimento de que o Brasil, como potência emergente, antes da crise atual, começava a atrair um maior número de refugiados e imigrantes econômicos.

Essa faceta da cultura haitiana é importante para compreender parte da motivação que leva o haitiano ao processo migratório, e também as experiências das mulheres, o lugar por elas ocupado neste contexto. Ainda e especialmente das participantes desta pesquisa que migraram em função do reagrupamento familiar.

\section{A MULHER NO CONTEXTO MIGRATÓRIO}

Às mulheres sempre foram atribuídas diferentes posições e lugares no contexto migratório, ao longo do tempo. Em função das relações de dominação masculina, sua presença quase sempre esteve à sombra dos homens devido ao fato de que a migração tem, geralmente, motivação laboral, e o homem é, no contexto de culturas patriarcais, o principal provedor de renda. Em muitos casos a decisão de migrar sequer foi ou é tomada pela própria mulher.

No campo dos estudos migratórios, durante muito tempo a presença da mulher esteve invisibilizada ou apenas abordada quantitativamente, como um mero percentual em relação à presença masculina. A posição da mulher nos processos migratórios, quando mencionada, tem sido ligada ao "trabalho do cuidado" ou "trabalho reprodutivo", ou seja, em profissões em que o cuidado (de crianças, idosos, deficientes, pessoas doentes ou lares) é realizado, majoritariamente, pela mulher (CARPENEDO; NARDI, 2013). Essa mudança de perspectiva ocorre no início do terceiro milênio quando o campo dos estudos migratórios passa a realizar uma análise sobre as migrações de mulheres a partir da análise das relações de gênero.

Dessa forma, mais do que uma mudança da posição das mulheres nos fluxos migratórios, de coadjuvantes nos processos de mobilidade masculina a protagonistas do seu próprio processo de migração, o que ocorre é uma transformação na análise destes processos (MARINUCCl, 2007) por meio das perspectivas de gênero. A migração das mulheres muitas vezes inverte uma posição de subordinação, na qual se encontravam nos países de origem ao tornarem-se mantenedoras de suas famílias com o dinheiro ganho no exterior (CARPENEDO; NARDI, 2013; 2017). Handerson e Joseph $(2015$, p. 28) afirmam que, no contexto da migração laboral das mulheres, notadamente no caso haitiano:

as relações sociais do trabalho, particularmente no setor doméstico, são determinadas pelas diferenças de gênero, de classe, de raça, de origem geográfica e da nacionalidade como dispositivos de discriminação. Assim, elas devem ser pensadas nas diferentes articulações cruzadas e na lógica consubstancial (HANDERSON; JOSEPH, 2015, p. 28).

Nas trajetórias em análise aqui, não se trata de uma migração por escolha, mas sim decorrente do reagrupamento familiar. Assim, as relações de subordinação que marcam as relações de gênero no Haiti, de certa forma, são transportadas para as experiências de ser migrante no Brasil. À situação de subordinação nas relações de gênero das duas jovens estudantes de ensino médio em uma escola pública, se articulam outros marcadores sociais da diferença (BRAH, 2006), pois elas são negras, imigrantes oriundas de um país afetado por conflitos internos, dificuldades econômicas e catástrofes 
ambientais, e que agora vivem na periferia de uma cidade fortemente industrializada e marcada culturalmente pela imigração italiana.

\section{A PESQUISA}

Este estudo de caso foi desenvolvido no primeiro semestre do ano de 2017 e projetado durante o ano de 2016. Contou com a participação de duas estudantes, de 17 e 20 anos, matriculadas em uma escola estadual de ensino médio da cidade de Caxias do Sul. $O$ instrumento construído para a realização das entrevistas foi pensado à luz de princípios de História Oral, que possibilitaram uma maior flexibilidade para abordar questões que surgiram na interação com as entrevistadas.

Trata-se de uma pesquisa que se propõe a compreender os fenômenos sociais que não podem ser mensurados numericamente, ou, como afirma Minayo (2011, p. 21):

[...]trabalha com o universo dos significados, dos motivos, das aspirações, das crenças, dos valores e das atitudes. Esse conjunto de fenômenos humanos é entendido aqui como parte da realidade social, pois o ser humano se distingue não só por agir, mas por pensar sobre o que faz e por interpretar suas ações dentro e a partir da realidade vivida e partilhada com seus semelhantes.

Dessa forma, intentamos entender, a partir das narrativas das estudantes que colaboraram com a pesquisa, as prováveis violências às quais elas possam ter sido submetidas no país de origem, na cidade de Caxias e na escola. Quiçá assim poderemos colaborar para que o campo da Educação se articule em um movimento de ação contra essas violências e de inclusão ampla e efetiva de estudantes que vivem situações similares e, sobretudo, para a construção de valores e princípios acolhedores, inclusivos, respeitosos e solidários, evitando assim que a migração reproduza a vitimização vivida no país de origem.

Yin (2005, p. 32) entende que "Um estudo de caso é uma investigação empírica que investiga um fenômeno contemporâneo dentro do seu contexto de vida real, especialmente quando os limites entre o fenômeno e o contexto não estão claramente definidos". Entendemos que "não estar claramente definido", nos limites deste contexto específico, significa a impossibilidade de medir ou quantificar o sentimento gerado pelas diversas opressões pelas quais um indivíduo em condição de vulnerabilidade possa estar sendo, ou ter sido, submetido em decorrência das violências próprias do processo de mobilidade ao qual se submeteu. Ainda, de acordo com Castro (1994, p. 61), seria um estudo de caso, "pois, ele apresenta as condições de conter as descrições densas [...] um retrato da situação estudada [...]. Oferece também a possibilidade de apresentar as múltiplas concepções que emergem do estudo realizado".

Além disso, adaptamos, para este estudo, o instrumento utilizado na pesquisa divulgada pelo Instituto de Pesquisa Econômica Aplicada (IPEA), em 2015. Considerando que o objetivo da pesquisa do IPEA era realizar um mapeamento da situação de todas as categorias de pessoas em situação de mobilidade humana no Brasil, numa perspectiva muito mais ampla, escolhemos limitar os questionamentos relativos às subcategorias identificadas a priori: violência física, violência cultural, violência estrutural e psicológica. 
O roteiro foi dividido em duas primeiras fases ${ }^{4}$, que tiveram influência das orientações da Plataforma de Desenvolvimento em migração e retorno (Return migration and Development Platform - RDP) do Centro de Estudos Avançados Robert Schuman (Robert Schuman Centre for Advanced Studies - European University Institute). O roteiro das entrevistas individuais permaneceu aberto a possíveis questões que pudessem emergir ao longo da entrevista (open-ended questions), mas a análise foi centrada para entender as categorias estabelecidas a priori (violências física, estrutural, cultural e violência psicológica) no país de origem e na cidade de destino.

Além disso, para a construção e adaptação do instrumento também utilizamos o Biographic-Narrative Interpretative Method (BNIM), que, segundo Wengarf (2004), deve ocorrer e ser organizado em três etapas. A primeira etapa objetiva construir um panorama geral sobre a história e a trajetória do participante. No segundo momento, partindo do que foi anotado, verificado e percebido na primeira etapa, através de notas e das transcrições, seriam abordados pontos específicos para que o participante possa, novamente, elucidar e aprofundar questões mais específicas. Na terceira etapa é possível abordar qualquer questão que seja necessária e importante para esclarecer dúvidas que tenham ficado ao longo da narrativa do entrevistado (WENGRAF, 2004, p. 2-3).

De acordo com a pesquisa divulgada pelo IPEA (BRASIL, 2015), mulheres e jovens compõem dois de três eixos de vulnerabilidade nos contextos migratórios (gênero, idade e deficiência). E, ainda, de acordo com Guy Standing (2014) existem três tipos de precariado e, destes, "o segundo tipo é constituído pelos migrantes e pelas minorias, que, por não terem presente nenhum lugar para chamarem de seu, vivem imbuídos de um forte sentimento de privação relativa" (STANDING, 2014, p. 14). O Conselho Nacional de Saúde CNS (BRASIL, 2016) compreende a vulnerabilidade como "situação na qual pessoa ou grupo de pessoas tenha reduzida a capacidade de tomar decisões e opor resistência na situação da pesquisa, em decorrência de fatores individuais, psicológicos, econômicos, culturais, sociais ou políticos" (BRASIL, 2016, Capítulo 2, Arto $2^{\mathrm{a}}-\mathrm{XXVI)}$.

Em virtude do entendimento deste contexto vulnerável e precário das estudantes, optamos por utilizar a metodologia de História Oral como princípio para a construção do instrumento de pesquisa. E também pela possibilidade de aprofundamento da análise nas questões particulares das participantes, das suas trajetórias e experiências e da construção de suas narrativas. Alberti (1990, p.18) define a História Oral como:

um método de pesquisa (histórica, antropológica, sociológica, etc.) que privilegia a realização de entrevistas com pessoas que participaram de, ou testemunharam, acontecimentos, conjunturas, visões de mundo, como forma de se aproximar de seu objeto de estudo. [...] produz fontes de consulta (as entrevistas) para outros estudos. [...] Trata-se de estudar acontecimentos históricos, instituições, grupos sociais, categorias profissionais, movimentos, [...] à luz de depoimentos de pessoas que dele participaram.

Ainda, Timm et al. (2013, p. 13) reitera que a " História Oral está atrelada a processos culturais, sociais e históricos, que são problematizados por meio do diálogo com as experiências dos sujeitos, narrativas estas impregnadas de significações apropriadas ao longo da vida.". Desse modo, as fontes foram analisadas de forma entrecruzada, o que nos permitiu refletir sobre a narrativa das estudantes em condição de 
mobilidade humana, "não como um tabuleiro de xadrez que tem todos os quadrados iguais, mas muito mais como uma colcha de retalhos, em que os pedaços são diferentes, porém formam um todo coerente depois de unidos" (ALVES, 2008, p.136).

Assim, o emprego dessa metodologia proporcionou extrapolar a simples verificação das opressões e violências pelas quais as estudantes foram e estão submetidas, pois permitiu compreender como o presente destas estudantes está ligado ao passado e às trajetórias familiares. Também permitiu perceber como as perspectivas de futuro delas estão situadas na história e na cultura de seu povo. Foram realizados ao todo quatro encontros com as participantes, sendo um de apresentação e esclarecimentos da pesquisa e outros três de entrevista. As duas entrevistas foram transcritas, e com o auxílio do software NVivo possibilitou otimizar o tempo de trabalho para perceber as categorias de violências, estabelecidas a priori, e onde (e se) as narrativas apontam para elas.

Por consequência, este estudo de caso consegue elucidar, no contexto das estudantes imigrantes, a quais violências elas estão expostas para que se possa pensar em como combatê-las. Não estabelecemos, primeiramente, um recorte étnico-racial ou de gênero, foi o próprio campo que os indicaram. Assim, tratamos neste trabalho apenas da dimensão de gênero que, indiscutivelmente, vem articulada a outras opressões e violências.

\section{RESULTADOS E DISCUSSÃO}

Após o breve panorama do significado da diáspora para o povo haitiano, bem como da mudança no campo dos estudos migratórios ao longo do tempo, no que tange à presença da mulher nesses estudos, cabe estabelecer algumas conexões com um dos recortes, fruto desta pesquisa: pensar as violências decorrentes do contexto migratório e como as questões relativas ao gênero se articulam nessas violências.

Como já dito, a análise das entrevistas contemplou as formas de violência física, estrutural, cultural e psicológica baseando-se nas teorias de Johan Galtung e Frantz Fanon. Assim sendo, vale ressaltar que a violência de gênero é, para Johan Galtung (1975, 1976, 1996), uma violência indireta, pois muitas vezes está naturalizada, pois é arraigada na cultura das sociedades, como o racismo, o machismo e a misoginia. Para Galtung (1975, 1976), estas formas de violência só se tornam violência direta quando agridem a integridade física da pessoa. Destarte, segundo Cremin e Guilherme $(2015$, p. 3), o machismo e a misoginia seriam formas de violência cultural que "ocorre em suporte à violência estrutural, mascarando-a (ex: indiferença ou suporte à violência doméstica)". Ou seja, a violência cultura/ está intrinsecamente interligada à violência estrutura/ que está nas bases e estruturas das sociedades e instituições (GUILHERME; SILVA, 2016).

Frantz Fanon, por sua vez, identifica as implicações da colonização psicológica dos sujeitos (de seus pensamentos, modos de vida e cultura) quebrando assim seu Eu, sua maneira de ser, seu amor-próprio e sua autoestima. Por isso, Fanon (1963) adiciona a violência psicológica como uma importante categoria de violência. Em seu entendimento, Fanon não categoriza as expressões de violência entre diretas ou indiretas; de fato, todas seriam formas diretas, visto que agridem tanto ao corpo como à psique do ser humano. (GUILHERME; SILVA, 2016) 
Galtung e Fanon estão muito próximos no seu entendimento sobre as violências. Como já explicitado, para Galtung $(1952,1963)$ a violência cultural está intrínseca à violência estrutural e as duas estão categorizadas como violência indireta. Fanon (1963), por sua vez, não categoriza a violência cultural, mas adiciona a violência psicológica à violência física e à violência estrutural.

Tendo isso em vista, no caso das estudantes haitianas participantes da pesquisa, foi a figura paterna quem deu início ao processo de mobilidade. Bem como, em muitos outros casos, contaram com a ajuda e o empenho de toda a família, pois colocá-lo na diáspora significa que ele, ao se estabilizar no lugar de destino, poderia compartilhar seus ganhos com a família que fica ou, ainda, fazer remessas de dinheiro para que o restante da família também pudesse migrar. Neste ponto, ambas as estudantes explicitam que antes do processo migratório, ainda quando adolescentes, não sentiam vontade de migrar e, inclusive, sentiram medo de sair de suas cidades. Logo, migrar não foi uma decisão ou um projeto próprio, mas sim um projeto familiar.

As duas estudantes migraram com a mãe e irmãos, sendo que uma das mães engravidou após chegar ao Brasil. Temos, portanto, duas famílias transnacionais reagrupadas, onde a figura paterna é o agente primeiro da migração e que coloca a família -mulher e filhas- no processo migratório. Ambas as mães trabalhavam no Haiti, uma com vendas e outra como enfermeira. E, de acordo com as duas estudantes, ambas as mães estão agora desempregadas.

Nesse sentido, é unânime entre as duas, que foram entrevistadas separadamente, a crença de que o fato de serem mulheres e imigrantes dificulta a conquista de um emprego. Uma delas, quando questionada sobre ter se sentido tratada de forma diferente por ser imigrante, responde: "É, tipo, quando uma pessoa sai pra procurar emprego e tem vaga, mas não é pra estrangeiro é para quem for do Brasil, brasileiros"s. E, quando perguntada sobre a ocupação da mãe: "ela procurou muitos já e não conseguiu emprego, eu acho. Faz muito tempo que minha mãe está procurando emprego, mas não consegue. Aífalei pra ela ficar em casa. Só meu pai que trabalha"t.

Ao serem questionadas se, em algum momento, se sentiram tratadas de forma diferente por serem imigrantes, ou por serem mulheres e negras, as estudantes respondem que não, que em nenhum momento sofreram algum tipo de preconceito. Todavia, ambas conferem à dificuldade de encontrar emprego (das mães e delas próprias) ao fato de serem mulheres imigrantes. Uma delas, a mais velha, relatou ter procurado emprego durante dois anos e não ter obtido sucesso em nenhuma seleção até ser selecionada para realizar um curso gratuito de Atendimento ao Cliente e Vendas.

Ou seja, nenhuma delas explicita ter sofrido, diretamente, violência de gênero, mas as duas creditam o desemprego das mães ao fato de serem mulheres, por terem filhos pequenos e por serem imigrantes. Embora as entrevistadas não identifiquem a discriminação, podemos associar o desemprego à violência de gênero arraigada a uma sociedade marcada pela dominação masculina, desigual, racista e xenófoba. Há também que considerar que as duas relatam não terem se sentido vítimas de racismo ou xenofobia, mesmo que saibam da ocorrência desses fenômenos na cidade. $O$ fato de as relações de gênero serem fortemente hierárquicas e marcadas pela dominação masculina pode indicar que as estudantes naturalizam as violências às quais têm sido submetidas. Segundo Montel (2016, p. 10), “A naturalização da violência leva a um processo de legitimação social, violências que são aceitas, culminando com a impunidade, por serem 
naturais e permitidas, não precisam ser condenadas". Porém, em outros momentos essas violências aparecem, como dito anteriormente.

Durante a análise foi possível concluir que o motivo da migração de ambas estudantes é decorrente de uma condição de violência estrutural no Haiti e possibilitada por uma catástrofe ambiental, em particular o terremoto de 2010 que matou entre duzentas e trezentas mil pessoas, deixou meio milhão de pessoas em situação de rua, causou sérios danos à infraestrutura já precária do país e surtos de cólera (Haiti Earthquake Facts and Figures, 2017). É essa violência estrutural que encorajou tantos haitianos a se juntarem à diáspora haitiana em outros países.

Não sendo o bastante, ao chegar ao Brasil elas também sofrem violência estrutural e cultural, na forma de uma situação de precariedade, racismo e xenofobia, e misoginia. Juntam-se a essas, a violência psicológica inerente ao processo de migração e de estabelecimento em uma cultura e uma sociedade tão diferente da de origem. Das categorias de violência estabelecidas (física, psicológica, estrutural e cultural), apenas a violência física não foi encontrada nas narrativas das estudantes.

Porém, para além das violências vivenciadas no cotidiano, ambas relatam uma esperança em um futuro próximo. Uma delas tem planos de voltar ao Haiti, mas somente após concluir o ensino superior. Quer cursar medicina para ajudar as pessoas pobres que ainda vivem em seu país. A outra, por sua vez, não pretende ficar no sul do Brasil, tampouco voltar ao Haiti; pensa em seguir sua vida em outro lugar, onde o frio não esteja presente, onde haja maiores oportunidades de emprego e estudo. Dessa forma, visualizamos aquilo que Handerson (2015) aponta tão claramente: a diáspora como um valor intrínseco à cultura haitiana, bem como o sentimento de solidariedade coletiva, traços marcantes e importantes da cultura do povo haitiano.

\section{CONCLUSÕES}

O processo migratório destas estudantes foi marcado por uma série de violências, desde a motivação inicial do pai para migrar, passando pelas dificuldades de adaptação e inserção no mercado de trabalho na sociedade de destino. Assim, mesmo as estudantes afirmando, mais de uma vez, não terem sofrido preconceito, esse está perceptível nas respostas relacionados a outros temas. A sociedade na qual se inseriram não estava preparada para recebê-las e está tendo que aprender a viver a interculturalidade na prática, e essa mesma realidade se reproduz na escola.

No que tange ao ambiente escolar, as estudantes não demonstraram ter sofrido algum tipo de violência direta. Apenas dão alguns indícios de violência estrutural, como o fato de a escola não se mostrar preocupada com algumas questões que são específicas da condição de vulnerabilidade decorrentes do processo migratório. No que diz respeito à instituição escolar, nenhuma prática ou medida é acionada para uma sensibilização dessa condição. Assim, se por um lado as professoras, professores e colegas tenham se mostrado acolhedores (de acordo com as falas das estudantes), por outro lado a instituição escolar reproduz violências estruturais por desconsiderar a situação peculiar desses estudantes imigrantes. 
Seria importante, nesse contexto, haver um suporte especial no que tange às dificuldades com a língua, ou ainda uma simples avaliação das condições de vida da família, antes de chegar e também na cidade, sobre o sistema de ensino no país de origem e sobre quais as principais dificuldades encontradas. Algumas pequenas mas importantes ações poderiam colaborar para uma melhor inclusão destas estudantes, por exemplo, a disseminação de conhecimentos sobre as razões da migração desses indivíduos junto aos professores e estudantes brasileiros, bem como a oferta de informações sobre a cultura e a sociedade brasileira para a população imigrante.

O acolhimento, no contexto escolar, acaba ocorrendo apenas através das relações interpessoais entre as estudantes e seus pares e professores, mas sem nenhum suporte institucional. Pode-se argumentar aqui que a verdadeira inclusão dessas jovens imigrantes na sociedade brasileira depende, e muito, do seu processo de inclusão em nossas escolas.

THE HAITIAN GIRLS AT SCHOOL: THE WEIGHT OF THE PAST, THE HARSHNESS OF THE PRESENT AND THE HOPE FOR THE FUTURE

ABSTRACT: This article, the result of a case study, aims to investigate the issue of gender violence within the haitian migratory context in the south of Brazil, analyzing the trajectory and daily life of two young haitian students, by interviews conducted using the principles of Oral History. For that, we characterised the meaning of migration (diaspora) for haitian people and the epistemological changes in the field of migration studies, regarding the presence of women so to reflect upon the gender violence evidenced in the narratives of the participants of this study and how the school have not considered their situation.

KEYWORDS: Haitian migration. Education. Violence. Gender.

\section{LAS HAITIANAS EM LA ESCUELA: EL PESO DEL PASADO, LA DUREZA DEL PRESENTE Y LA ESPERANZA EM EL FUTURO}

RESUMEN: Este artículo, fruto del recorte de un estudio de caso, tiene como objetivo abordar la violencia de género en el contexto migratorio haitiano hacia el sur de Brasil, mediante la trayectoria y el cotidiano de dos jóvenes estudiantes haitianas, a través de entrevistas realizadas con principios de Historia Oral. Para ello, levantamos un breve histórico del significado de la migración (diáspora) para el pueblo haitiano y los cambios epistemológicos en el campo de estudios migratorios en lo que se refiere a la presencia de la mujer en estos estudios, para entonces, reflexionar sobre la violencia de género evidenciada en las narrativas de las " Estudiantes participantes de la investigación y de cómo la institución escolar no ha actuado en ese sentido.

PALABRAS CLAVE: Migración haitiana. Educación. Violencia. Género.

\section{NOTAS}


1) Ver HANDERSON, J. “Diáspora. Sentidos sociais e mobilidades haitianas”, 2015. Disponível em: < http://dx.doi.org/10.1590/S0104-71832015000100003 >. Acesso em: 20 fev. 2019.

2) De acordo com dados oficiais do Ministério dos Haitianos Residentes no Exterior, algo em torno de 4 a 5 milhões de haitianos vivem fora do país. Representando, praticamente, a metade dos habitantes do Haiti, estimados em 10,4 milhões em 2013 pelo Institut Haitien de Statistique et d'informatique (HANDERSON, 2015, p.52).

3) Segundo o site Tranding Economics, o Haiti possui uma taxa de desemprego de 6,8\% para uma população de 10,91 milhões (2017). PIB per capita de 729 USD e uma taxa de inflação de 15,8\% (HAITI, 2017).

4) Na primeira fase foi abordada a vida das participantes, todo o background que compõem sua história e trajetória, sua situação antes de deixar o país de origem e o que o levou à migração. Na segunda a experiência de migração no Brasil e nas suas experiências escolares antes e depois da migração.

5) Entrevista concedida pela participante da pesquisa, Entrevista I, Junho de 2017. Entrevistador: o autor. Porto Alegre, 2017.

6) Entrevista concedida pela participante da pesquisa, Entrevista I, Junho de 2017. Entrevistador: o autor. Porto Alegre, 2017.

\section{REFERÊNCIAS}

ALBERTI, V. História oral: a experiência do CPDOC. Rio de Janeiro: Instituto de Documentação, Editora da Fundação Getúlio Vargas, 1990.

ALVES, N. Nós somos o que contamos: a narrativa de si como prática de formação. In: SOUZA, E. C.; MIGNOT, A. C. V. (Orgs.). Histórias de vida e formação de professores. Rio de Janeiro: Quartet; Faperj, 2008

BRAH, A. Diferença, diversidade, diferenciação. Cadernos Pagu, Campinas, n. 26, p. 329376, 2006.

BRASIL, Ministério da Justiça. Migrantes, apátridas e refugiados: subsídios para o aperfeiçoamento de acesso a serviços, direitos e políticas públicas no Brasil. Ministério da Justiça, Secretaria de Assuntos Legislativos. Brasília, Instituto de Pesquisa Econômica Aplicada, 2015. Disponível em: < http://pensando.mj.gov.br/wpcontent/uploads/2015/11/PoD_57_web2.pdf >. Acesso em: 20 fev. 2019

. Conselho Nacional de Saúde. Resolução 510 de 7 de abril de 2016. Brasília, DF. Ministério da Saúde, 2016. Disponível em:

<http://conselho.saude.gov.br/resolucoes/2016/Reso510.pdf >. Acesso em: 20 fev. 2019 
GUILHERME, A.; SILVA, L. R.; NARDI, H. C.

Decreto de Lei no 13.445 de 24 de maio de 2017. Aprova a Lei de Migração disponível em: 2017. Disponível em: <http://www.planalto.gov.br/ccivil_03/_ato20152018/2017/lei/L13445.htm > Acesso em: 20 fev. 2019

CARPENEDO, M., NARDI, H. C. Mulheres Brasileiras na Divisão Internacional do trabalho reprodutivo: construindo subjetividade (s). Revistas de Estudios Sociales, Colombia: Universidad de los Andes, p. 96 a 109, 2013.

CASTRO, M. L. S. Metodologia da Pesquisa Qualitativa: Revendo as Idéias de Edgon Guba. In: ENGERS, M. E. A. Paradigmas e Metodologias de pesquisa em Educação: notas para reflexão. Porto Alegre: EDIPUCRS, p. 53-64, 1994.

CREMIM, H., GUILHERME, A. Violence in Schools: Perspectives (and hope) from Galtung and Bube. Educational Philosophy and Theory, Earlyview, p. 1-15, 2015.

FANON, F. Black Skin, White Masks. França: Éditions du Seuil, 1952.

The wretched of the Earth. Nova York: Grove Weidenfeld, 1963.

GALTUNG, J. Peace: Research, education, action. Essays in peace, Research V. I. Copenhagen: Christan Ejlers, 1975.

Three approaches to peace: Peacekeeping, peacemaking, peacebuilding, Peace, war and defense: Essays in peace research, V. II, pp. 297-298). Copenhagen: Christian Ejlers, 1976.

Peace by peaceful means: Peace and conflict, development, \& civilization. Londres: Sage Publications \& International Peace Research Association, 1996. GUILHERME, A.; CASARTELLI, A.; SILVA, L. R.; FRAGA, I. A Educação Profissional E Sua Importância No Contexto De Migrações Laborais: Um Estudo De Caso, Comparison Plurielles, Vol. 2, Paris: UPEC, 2017.

GUILHERME, A.; SILVA, L. Violência Escolar: perspectivas da Filosofia. In: ADAM, J. (org.). Espaços e Conflitos Escolares. perspectivas a partir de imagens produzidas por alunos de escolas públicas, Rio Claro: UNESP, 2016.

HAITI EARTHQUAKE FACTS AND FIGURES, DEC. Disponível em: <https://www.dec.org.uk/articles/haiti-earthquake-facts-and-figures>. Acesso em 23 ago. 2017.

HAITI, INDICADORES ECONÔMICOS, Tranding EConomics. Disponível em: <https://pt.tradingeconomics.com/haiti/indicators>. Acesso em 23 ago. 2017.

HANDERSON, J. Diáspora. Sentidos sociais e mobilidades haitianas. Horizontes Antropológicos. Porto Alegre, ano 21, n. 43, p. 51-78, jan./jun., 2015. 
; JOSEPH, R.M. As Relações de Gênero, de Classe e de Raça: mulheres migrantes haitianas na França e no Brasil. Revista de Estudos e Pesquisas sobre as Américas, Brasília, UnB. v. 9, n. 2, 2015.

HERÉDIA, V. B. M. Migrações Internacionais, o caso dos Senegaleses no Sul do Brasil. Caxias do Sul, RS: Belas Letras, 2015.

MACHADO, I. J. R.; KEBBE, V. H.; SILVA, C. R. Notas sobre a família transnacional. Revista Interdisciplinar da Mobilidade Humana. Rio de Janeiro, v. 16, n. 30, 2008.

MARINUCCI, R. Feminização das migrações? Revista Interdisciplinar da Mobilidade Humana. Rio de Janeiro, v. 15, n. 29, 2007.

MINAYO, M. C. S. (org.). Pesquisa Social: teoria, método e criatividade. Petrópolis: Vozes, 2011.

MONTEIRO, S. R. R. P. O Marco Conceitual da Vulnerabilidade Social. Sociedade em Debate, Pelotas, 2011.

MONTEL, L. A negação do "Outro": narrativas de imigrantes haitianas no Brasile a construção de empatia. In: Migração e Direitos Humanos nas Fronteiras, 2016, Campo Grande. Anais: Congresso Internacional de Direitos Humanos, Campo Grande, UFMS. Disponível em: < https://cidhsite.files.wordpress.com/2017/05/ar_gt8_6.pdf >. Acesso em 21 ago. 2017.

RODRIGUES, M. C.; NARDI, H. C. Diversidade Sexual e Trabalho: reinvenções do dispositivo. Bagoas: Revista de Estudos Gays, v. 2, p. 127-143, 2008.

STANDING, G. O Precariado e a Luta de Classes. Revista Crítica de Ciências Sociais, v. 103, maio, 2014.

TIMM, J. W.; ARAGÃO, M.; KREUTZ, L. A História Oral e sua contribuição para o estudo das histórias escolares. Conjectura: Filosofia Educação, Caxias do Sul, v. 18, n. 2, p. 28-41, maio/ago., 2013

YIN, R. Estudo de Caso. Planejamento e Métodos. Porto Alegre, Bookman, 2005.

AleXANDRe GuIllherme: Coordenador do Grupo de Pesquisa em Educação e Violência (GruPEV), da PUCRS.

E-mail: alexandre.guilherme@pucrs.br 
GUILHERME, A.; SILVA, L. R.; NARDI, H. C.

LuCAS ReCH da SILVA: Mestrando PPGEdu da PUCRS.

E-mail: lucas.silva.031@acad.pucrs.br

Henrique Caetano Nardi: Professor do PPGPSI da PUCRS.

E-mail: henardi@gmail.com 